\title{
Escherichia coli BdcA controls biofilm dispersal in Pseudomonas aeruginosa and Rhizobium meliloti
}

\author{
Qun Ma, Guishan Zhang and Thomas K Wood
}

\begin{abstract}
Background: Previously we showed that BdcA controls Escherichia coli biofilm dispersal by binding the ubiquitous bacterial signal cyclic diguanylate (c-di-GMP); upon reducing the concentration of c-di-GMP, the cell shifts to the planktonic state by increasing motility, decreasing aggregation, and decreasing production of biofilm adhesins.

Findings: Here we report that BdcA also increases biofilm dispersal in other Gram-negative bacteria including Pseudomonas aeruginosa, Pseudomonas fluorescens, and Rhizobium meliloti. BdcA binds c-di-GMP in these strains and thereby reduces the effective c-di-GMP concentrations as demonstrated by increases in swimming motility and swarming motility as well as by a reduction in extracellular polysaccharide production. We also develop a method to displace existing biofilms by adding BdcA via conjugation from E. coli in mixed-species biofilms.
\end{abstract}

Conclusion: Since BdcA shows the ability to control biofilm dispersal in diverse bacteria, BdcA has the potential to be used as a tool to disperse biofilms for engineering and medical applications.

\section{Background}

Bacteria prefer to grow as biofilms [1]; i.e., as aggregates of bacteria that form usually at interfaces. Cells in biofilms are protected and held together by the extracellular matrix that includes polysaccharide, lipids, protein, and DNA [2]. Biofilms are notoriously difficult to remove $[3,4]$ and are related to $80 \%$ of all human infections [5]. In addition, biofilm formation leads to significant energy losses in heat exchange equipment [6] and causes operational problems in the oil industry via metal corrosion, flow reduction, contamination, and reservoir plugging [7]. Conversely, biofilms are becoming increasingly important for chemical transformations; for example, biofilms lead to better productivity for biofuels such as ethanol [8], and biofilm communities form on electrodes surfaces to produce power for microbial fuel cells [9]. Also, for biorefineries, it will be important to be able to remove biofilms from fixed film reactors so that diverse products may be synthesized [10]. Hence, effective strategies to remove biofilms for medical applications as well as to control biofilm formation for engineering applications are important. Biofilm development is a dynamic process that includes movement to the surface [11], initial reversible attachment, irreversible

\footnotetext{
* Correspondence: Thomas.Wood@chemail.tamu.edu

* Correspondence: Thomas.Wood@chemail.tamu.edu
Department of Chemical Engineering, Texas A \& M University, College Station, TX 77843-3122, USA
} Station, TX 77843-3122, USA

(c) 2011 Wood et al; licensee BioMed Central Ltd. This is an open access article distributed under the terms of the Creative Commons Attribution License (http://creativecommons.org/licenses/by/2.0), which permits unrestricted use, distribution, and reproduction in any medium, provided the original work is properly cited.

attachment, formation of small aggregates, maturation of the biofilm, and biofilm dispersal [12]. Biofilm dispersal is controlled by various factors, including external forces and the physiological changes of the bacteria themselves [4].

Previously we discovered the biofilm dispersal protein BdcA in Escherichia coli, which works by binding to the intracellular signal cyclic diguanylate (c-di-GMP) but does not act as a phosphodiesterase [13]. Reducing c-di-GMP concentrations increases motility and extracellular DNA production and decreases extracellular polysaccharide production (EPS), cell length, and aggregation which leads to biofilm dispersal [13]. We also performed protein engineering on this protein and successfully abolished biofilm formation via single amino acid replacement at E50Q [13]. Hence biofilm dispersal can be achieved by simply by producing BdcA in E. coli. However, it has not been demonstrated that this protein is functional and can cause dispersal of biofilms in other bacteria.

Since BdcA works through c-di-GMP [13], and c-diGMP exists in almost all bacteria [10] and regulates biofilm formation by controlling cell motility in Gram-negative bacteria [14], we hypothesized that BdcA may also work in most Gram-negative bacteria. Hence, here we constructed a broad-host plasmid to produce BdcA (pMMB206-BdcA) and tested the effect of BdcA production on biofilm dispersal for the opportunistic pathogen 
Pseudomonas aeruginosa (responsible for chronic cystic fibrosis infections $[15,16])$, the biocontrol agent Pseudomonas fluorescens (utilized for protecting plants from fungi infection $[17,18]$ ), as well as the nitrogen-fixing bacterium Rhizobium meliloti $[19,20]$. For all three bacteria, we find that BdcA is an effective tool for dispersing biofilms.

\section{Methods}

Bacterial strains, media, and growth conditions

The strains and plasmids used in this study are listed in Table 1. Expression of $b d c A$ was induced by $0.1 \mathrm{mM}$ isopropyl- $\beta$ - $D$-thiogalactopyranoside (IPTG) (Sigma, St. Louis, MO). Luria-Bertani (LB) [21] was used for all the experiments. Chloramphenicol $(50 \mu \mathrm{g} / \mathrm{mL}$ for $R$. meliloti and $250 \mu \mathrm{g} / \mathrm{mL}$ for Pseudomonas sp.) was used for strains harboring pMMB206 and pMMB206-BdcA. Carbenicillin $(50 \mu \mathrm{g} / \mathrm{mL})$ was used for strains harboring pP25-gfp. $37^{\circ} \mathrm{C}$ was used for all $P$. aeruginosa tests, and $30^{\circ} \mathrm{C}$ was used for $P$. fluorescens and $R$. meliloti tests.

\section{Plasmid construction}

The $b d c A$ gene was amplified from $E$. coli BW25113 using bdcAc f-primer (5'-CGCGCAGGATCCCACCATCACCACCATCATGGCGCTTTTACAGGTAAGACAGTTC3') and bdcAc-r primer (5'-GATGTGGAGTCTGCTG AGCTGCAGTTATGCGCCAAACGCGCCATCAATG-
3'), and the PCR product was cleaned with the QIAquick PCR purification kit (QIAGEN, Valencia, CA). The $b d c A$ PCR product and the pMMB206 vector were both digested with BamHI (New England Biolabs, Beverly, MA) and PstI (New England Biolabs) overnight at $37^{\circ} \mathrm{C}$. The vector was treated with alkaline phosphatase (New England Biolabs), and ligation was performed with T4 DNA ligase (New England Biolabs) overnight at $16^{\circ} \mathrm{C}$. The ligation product was electroporated into E. coli $\mathrm{DH} 5 \alpha$, and white colonies after blue/white screening were selected and sequenced with sequencing primers bdcAseq $\mathrm{f}$-primer (5'-ACACTTTATGCTTCCGGCTCGTATG-3') and bdcAseq r-primer (5'-GCGATTAAGTTGGGTAACGCCAG-3'). The correctly constructed pMMB206-BdcA (Figure 1) was introduced into the Rhizobium strain via electroporation and into the Pseudomonas strains via conjugation as previously described [22]. pMMB206-BdcA is a low-copy-number plasmid, and the expression of $b d c A$ is under the control of the tandem tac-lacUV5 promoter [23].

\section{Static biofilm assay using crystal violet}

Biofilm formation for the individual single strains was assayed in 96-well polystyrene plates using $0.1 \%$ crystal violet staining (Corning Costar, Cambridge, MA) as described previously [24] with small modifications.

Table 1 Strains and plasmids used in this study

\begin{tabular}{|c|c|c|}
\hline Strain/Plasmid & Genotype & Source \\
\hline \multicolumn{3}{|l|}{ Strain } \\
\hline E. coli BW25113 & lacl $^{9} \mathrm{rrnB}_{\mathrm{T} 14} \Delta a c Z_{\mathrm{WJ16}}$ hsdR514 $\triangle a r a B A D_{\mathrm{AH} 33} \Delta h a B A D_{\mathrm{LD} 78}$ & {$[34]$} \\
\hline E. coli DH5 $\alpha$ & 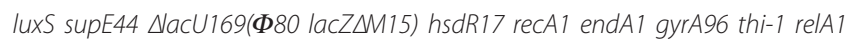 & {$[21,35]$} \\
\hline E. coli DH5a/pMMB206/pRK2013 & E. coli harboring pMMB206 and pRK2013 & This study \\
\hline E. coli DH5a/pMMB206-BdcA/pRK2013 & E. coli harboring pMMB206-BdcA and pRK2013 & This study \\
\hline P. aeruginosa PA14 & P. aeruginosa wild-type strain & {$[36]$} \\
\hline P. fluorescens & P. fluorescens wild-type strain & R. Frazee \\
\hline R. meliloti $102 \mathrm{~F} 34$ & R. meliloti wild-type strain & M. Sadowski \\
\hline PA14/pMMB206 & P. aeruginosa wild-type harboring pMMB206 & This study \\
\hline PA14/pMMB206-BdcA & P. aeruginosa wild-type harboring pMMB206-BdcA & This study \\
\hline PA14/pMMB206/pP25-gfp & P. aeruginosa wild-type harboring pMMB206 and pP25-gfp & This study \\
\hline PA14/pMMB206-BdcA/pP25-gfp & P. aeruginosa wild-type harboring pMMB206-BdcA and pP25-gfp & This study \\
\hline P. fluorescens/pMMB206 & P. fluorescens wild-type harboring pMMB206 & This study \\
\hline P. fluorescens/pMMB206-BdcA & P. fluorescens wild-type harboring pMMB206-BdcA & This study \\
\hline R. meliloti 102F34/pMMB206 & R. meliloti wild-type harboring pMMB206 & This study \\
\hline R. meliloti 102F34/pMMB206-BdcA & R. meliloti wild-type harboring pMMB206-BdcA & This study \\
\hline R. meliloti 102F34/pMMB206/pP25-gfp & R. meliloti wild-type harboring pMMB206 and pP25-gfp & This study \\
\hline R. meliloti 102F34/pMMB206-BdcA/pP25-gfp & R. meliloti wild-type harboring the pMMB206-BdcA and pP25-gfp & This study \\
\hline \multicolumn{3}{|l|}{ Plasmid } \\
\hline pMMB206 & $\mathrm{Cm}^{r}, \mathrm{Mob}^{+}, \mathrm{lacl}^{q}$, broad-host range plasmid & {$[23]$} \\
\hline pMMB206-BdcA & $\mathrm{Cm}^{\mathrm{r}}$; pMMB206 with $P_{\text {tac-lacuvs }: .6 d c A}$ & this work \\
\hline pRK2013 - n & $\mathrm{Km}^{\mathrm{r}}$; $\mathrm{Tra}^{+} \mathrm{Mob}^{+}$(RK2) Km::Tn7 ColEl origin, helper plasmid for mobilization & M. Bagdasarian, [37] \\
\hline pP25-gfp & Car'; constitutive green fluorescent protein production & {$[27]$} \\
\hline
\end{tabular}

$\mathrm{Cm}^{r}$, Carr ${ }^{r}$ and $\mathrm{Km}^{\mathrm{r}}$, denote chloramphenicol, carbenicillin, and kanamycin resistance, respectively. 


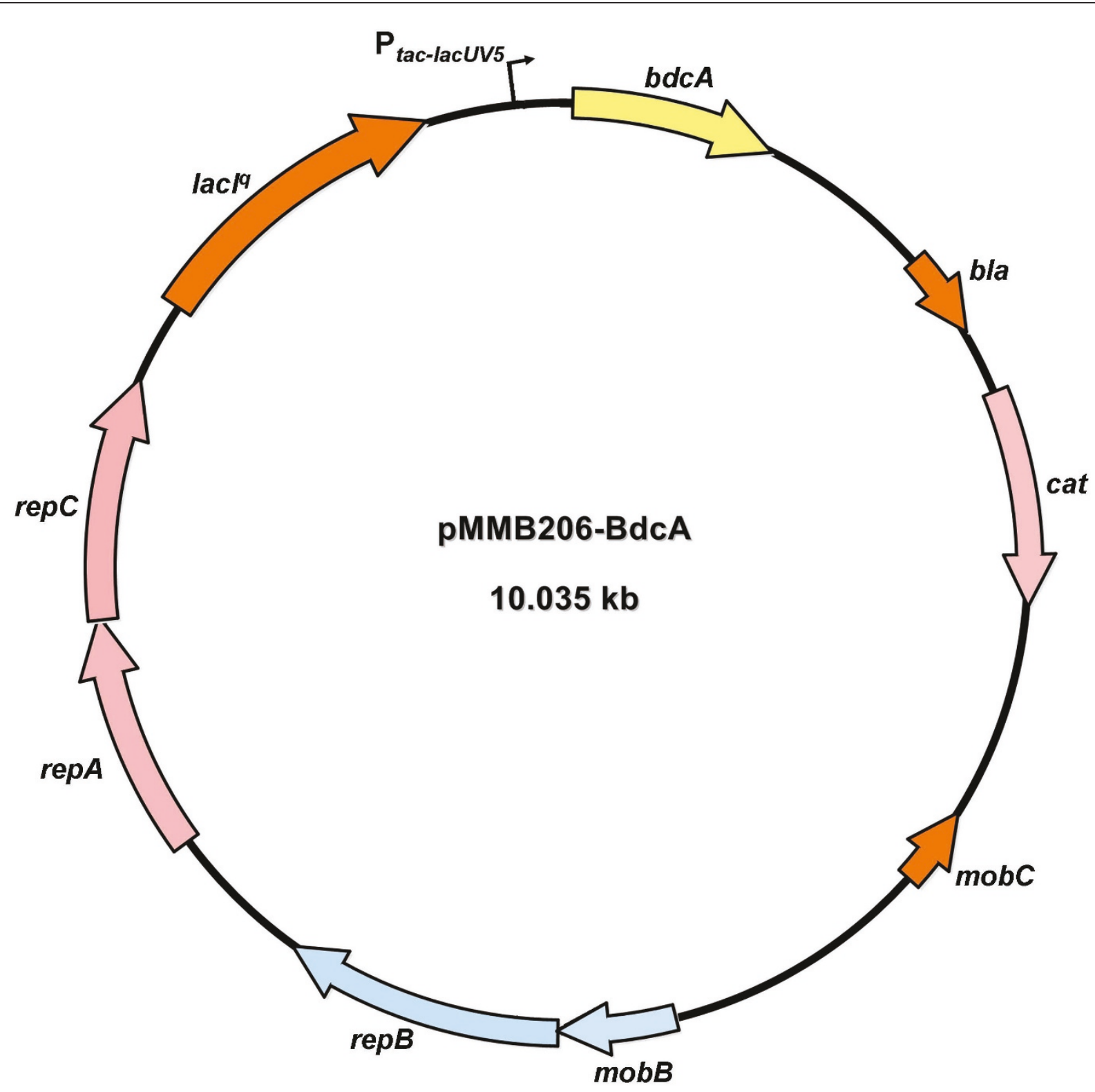

Figure 1 Plasmid map for pMMB206-BdcA. The bdcA gene is shown in yellow.

Briefly, each well was inoculated with overnight cultures at an initial turbidity at $600 \mathrm{~nm}$ of 0.05 and grown without shaking for $24 \mathrm{~h}$ with chloramphenicol, and then 0.1 mM IPTG was added to the culture to induce $b d c A$. For $P$. aeruginosa, the mixture was shaken at $150 \mathrm{rpm}$ for 1 min and then incubated for $2 \mathrm{~h}$ ( $26 \mathrm{~h}$ total) to establish the extent of mature biofilm formation. Biofilm dispersal was determined after $19 \mathrm{~h}$ of IPTG induction (43 h total). Comparison of these two values gave the percentage of biofilm dispersal. Similarly, for P. fluorescens and $R$. meliloti, biofilm formation was determined and compared after $2 \mathrm{~h}$ and $21.5 \mathrm{~h}$ of IPTG induction. At least two independent cultures were used for each strain. To remove growth effects, biofilm formation was normalized by dividing total biofilm by bacterial growth in the bulk liquid.

For BdcA dispersal in dual-species biofilms of E. coli/R. meliloti and $E$. coli/P. aeruginosa formed in 96-well plates, pMMB206-BdcA was mobilized using E. coli DH5a/ pMMB206-BdcA/pRK2013 by adding $300 \mu \mathrm{L}$ of turbidity 0.05 of these washed cells to the $R$. meliloti and P. aeruginosa biofilms formed for $24 \mathrm{~h}$. After $4 \mathrm{~h}, 0.1 \mathrm{mM}$ IPTG was added to produce BdcA, and cells were grown for an additional $26 \mathrm{~h}$. To approximate the conjugation 
efficiency, biofilm cells were taken from the air/liquid biofilm (top) of each well in the 96-well plates at the end of the experiment and plated on LB, LB + rifampicin, and LB + rifampicin + chloramphenicol selective plates. For rifampicin, $20 \mu \mathrm{g} / \mathrm{mL}$ inhibits $E$. coli, $R$. meliloti is resistant to $20 \mu \mathrm{g} / \mathrm{mL}$, and $P$. aeruginosa is resistant to $100 \mu \mathrm{g} / \mathrm{mL}$; chloramphenicol was used to select for cells harboring pMMB206 or pMMB206-BdcA. The conjugation efficiency of $R$. meliloti and $P$. aeruginosa was calculated by comparing the number of recipient cells harboring pMMB206 or pMMB206-BdcA with the total number of recipient cells for each species. In addition, five random colonies were selected from LB plates with $100 \mu \mathrm{g} / \mathrm{mL}$ rifampicin and $250 \mu \mathrm{g} / \mathrm{mL}$ chloramphenicol (selective plates for $P$. aeruginosa/pMMB206-BdcA) and another five colonies were selected from LB plates with $20 \mu \mathrm{g} / \mathrm{mL}$ rifampicin and $50 \mu \mathrm{g} / \mathrm{mL}$ chloramphenicol (selective plates for $R$. meliloti/pMMB206-BdcA) to verify the presence of the plasmid and to identify the host. The presence of the plasmid in recipient cells was confirmed via PCR of the $b d c A$ gene with the bdcAc f-primer and the bdcAc r-primer, and the bacterial species of the recipient cells was confirmed via sequencing of the $16 \mathrm{~S}$ rRNA genes (primers are the 1492R-primer 5'-GGTTACCTTGTTACGACTT3 ' and the 27F-primer 5'-AGAGTTTGATCCTGGCTCAG-3' [25]).

Similarly, for BdcA dispersal in triple-species biofilms of E. coli, R. meliloti, and P. aeruginosa, pMMB206-BdcA was mobilized using E. coli DH5a/pMMB206-BdcA/ pRK 2013 by adding $300 \mu \mathrm{L}$ of turbidity 0.05 of these cells to existing double-species biofilms formed by $R$. meliloti and $P$. aeruginosa for $24 \mathrm{~h}$. After another $11 \mathrm{~h}, 0.1 \mathrm{mM}$ IPTG was added to produce BdcA, and cells were grown for an additional $24 \mathrm{~h}$. To determine the percentage of each of the three strains in the biofilms, cells were taken from the air/liquid biofilm and from the liquid/bottom biofilm and diluted in LB for enumeration. The biofilm composition was determined based on the difference in rifampicin resistance of these three bacteria: $20 \mu \mathrm{g} / \mathrm{mL}$ inhibits E. coli, $100 \mu \mathrm{g} / \mathrm{mL}$ inhibits $R$. meliloti, and P. aeruginosa is resistant to $100 \mu \mathrm{g} / \mathrm{mL}$.

\section{Flow cell biofilms and image analysis}

The flow cell experiments were performed as previously described [26]. pP25-gfp [27] was used to produce the green fluorescent protein (GFP) for imaging each strain. The flow cells were inoculated with cultures at an initial turbidity at $600 \mathrm{~nm}$ of 0.05 at a flow rate of $10 \mathrm{~mL} / \mathrm{min}$ for $2 \mathrm{~h}$, then fresh LB medium with chloramphenicol and carbenicillin was added at $10 \mathrm{~mL} / \mathrm{min}$. IPTG $(0.1 \mathrm{mM})$ was added to each flow cell system after $24 \mathrm{~h}$, and images were taken $48 \mathrm{~h}$ and $96 \mathrm{~h}$ after IPTG addition for P. aeruginosa and $43 \mathrm{~h}$ and $91 \mathrm{~h}$ after IPTG addition for $R$. meliloti. Biofilm images from nine random positions were visualized with IMARIS confocal software (Bitplane, Zurich, Switzerland) and analyzed by COMSTAT confocal software as previously described [26]. Two independent cultures were used for each strain; i.e., eight flow cell experiments were conducted.

\section{Swarming motility, swimming motility, and EPS assays}

The swarming motility of $P$. aeruginosa and $P$. fluorescens was assayed with BM-2 plates [22], while the swarming motility for $R$. meliloti was measured with 0.6\% Eiken agar (Eiken Chemical Co., Tokyo, Japan) plates in LB medium with $0.5 \%$ glucose. Cells grown to a turbidity at $600 \mathrm{~nm}$ of $\sim 1.0$ were used for inoculation, and $0.1 \mathrm{mM}$ IPTG was applied for each strain to induce the expression of $b d c A$. The swarming halo was measured after $15 \mathrm{~h}$ incubation for $P$. aeruginosa and $R$. meliloti and after $20 \mathrm{~h}$ incubation for P. fluorescens. Two independent cultures were used for each strain and at least three plates were used for each independent culture.

Swimming motility was performed as previously described [28]. Overnight cultures were used to inoculate the plates ( $1 \%$ tryptone, $0.25 \% \mathrm{NaCl}$ and $0.3 \%$ agar), and the swimming halo was measured after $11 \mathrm{~h}$ for $P$. aeruginosa, after $20 \mathrm{~h}$ for $P$. fluorescens, and after $15 \mathrm{~h}$ for $R$. meliloti. Two independent cultures were used for each strain, and at least three plates were used for each independent culture.

The amount of total EPS was determined as described previously [29]. Briefly, $1 \mathrm{~mL}$ cell cultures grown in M9$0.4 \%$ mannitol medium were collected after $48 \mathrm{~h}$ and boiled in water for $10 \mathrm{~min}$. The supernatants were then used for an anthrone- $\mathrm{H}_{2} \mathrm{SO}_{4}$ assay to determine EPS concentrations. This assay was performed with two independent cultures.

\section{Results}

\section{BdcA plasmid does not affect growth}

In the absence of production of BdcA, all three pairs of bacteria grew at nearly the same rate $(0.5860 \pm 0.0003 / \mathrm{h}$ for $P$. aeruginosa/pMMB206 vs. $0.571 \pm 0.009 / \mathrm{h}$ for $P$. aeruginosa/pMMB206-BdcA at $37^{\circ} \mathrm{C} ; 0.512 \pm 0.005 / \mathrm{h}$ for P. fluorescens/pMMB206 vs. $0.506 \pm 0.002 / \mathrm{h}$ for $P$. fluorescens/pMMB206-BdcA at $30^{\circ} \mathrm{C}$; and $0.511 \pm 0.0008 / \mathrm{h}$ for $R$. meliloti/pMMB206 vs. $0.51 \pm 0.01 / \mathrm{h}$ for $R$. meliloti/pMMB206-BdcA at $30^{\circ} \mathrm{C}$ ) so the presence of $b d c A$ on the plasmid does not affect growth. Hence, the bacteria are expected to form similar amounts of biofilm prior to production of BdcA for biofilm dispersal.

\section{BdcA increases swarming and swimming motility and decreases EPS production}

To investigate the impact of BdcA production on cell physiology, we assayed cell motility and EPS production 
since these phenotypes are controlled by c-di-GMP [13]. Production of BdcA increased both the swarming of $P$. aeruginosa and $R$. meliloti ( $P$. fluorescens did not swarm under these conditions) (Figure 2A) as well as increased the swimming of $P$. aeruginosa, P. fluorescens, and $R$. meliloti (Figure 2B). Furthermore, EPS production was reduced in all three strains $(1.3 \pm 0.3$-fold for $P$. aeruginosa, $1.8 \pm 0.2$-fold for $P$. fluorescens, and $1.4 \pm 0.1$-fold for $R$. meliloti) upon BdcA production. These phenotypes are consistent with reduced $\mathrm{c}$-diGMP concentrations in these cells in the presence of BdcA $[13,22]$.

\section{BdcA increases biofilm dispersal in microtitre plates}

Static biofilm dispersal tests showed that $b d c A$ produced in trans caused $40 \%$ biofilm dispersal while the control strain with an empty vector had 5 to $10 \%$ biofilm dispersal under the same conditions in $P$. aeruginosa, P. fluorescens, and $R$. meliloti (Figure 3A). Critically, similar biofilm formation occurred prior to dispersal for all three strains; hence, production of BdcA only changed the dispersal stage of the biofilm (Figure 3A). Therefore, BdcA is active in vivo in strains other than E. coli, and BdcA can remove existing biofilms.
BdcA increases biofilm dispersal in flow cells

To corroborate the static 96 well results, we tested biofilm dispersal with the more rigorous flow cell assay by continuously adding fresh medium to the biofilms with $P$. aeruginosa and $R$. meliloti. Critically, for both bacteria, biofilms were formed to the same extent prior to BdcA causing dispersal (Table 2). For example, for $P$. aeruginosa, after $72 \mathrm{~h}$, there was slightly more biofilm biomass for the strain producing BdcA vs. the empty plasmid control and similar biofilm thickness and surface coverage (Table 2). After $67 \mathrm{~h}$, nearly identical biofilm parameters were obtained with $R$. meliloti.

Production of BdcA caused a 7-fold increase in biofilm dispersal (based on biomass) for $R$. meliloti and 15-fold increased biofilm dispersal in $P$. aeruginosa (Table 2 and Figure 4). For both strains, the biofilms were almost completely removed for the cells producing BdcA while the empty plasmid control maintained a robust biofilm (Figure 4). Hence, BdcA is extremely effective in causing biofilm dispersal in Gram-negative bacteria other than E. coli.

\section{BdcA causes dispersal in mixed-species biofilms}

To demonstrate that BdcA may be added to a mixedspecies biofilm via conjugation, 96-well static biofilm
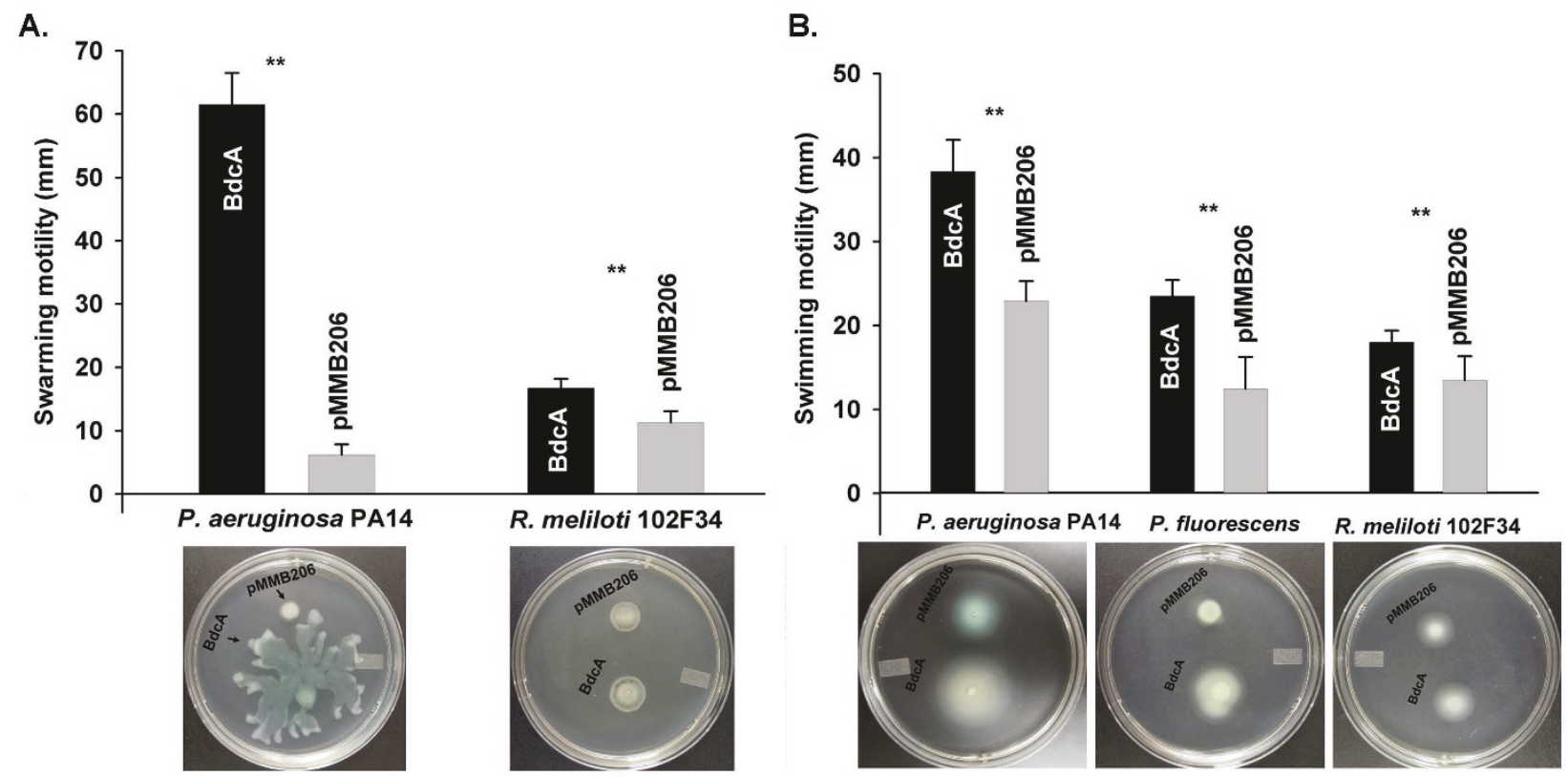

Figure 2 BdcA increases swarming and swimming motility. (A) Swarming motility of $P$. aeruginosa PA14 and R. meliloti $102 \mathrm{~F} 34$ with BdcA production. The $P$. aeruginosa BM-2 plates were incubated at $37^{\circ} \mathrm{C}$ with $250 \mu \mathrm{g} / \mathrm{mL}$ chloramphenicol for $15 \mathrm{~h}$, and the R. meliloti Eiken agar plates were incubated at $30^{\circ} \mathrm{C}$ with $50 \mathrm{\mu g} / \mathrm{mL}$ chloramphenicol for $15 \mathrm{~h}$. (B) Swimming motility of $P$. aeruginosa, $P$. fluorescens, and $R$. meliloti 102F34. The $P$. aeruginosa plates were incubated at $37^{\circ} \mathrm{C}$ with $250 \mu \mathrm{g} / \mathrm{mL}$ chloramphenicol for $11 \mathrm{~h}$, the $P$. fluorescens plates were incubated at $30^{\circ} \mathrm{C}$ with $250 \mu \mathrm{g} / \mathrm{mL}$ chloramphenicol for $20 \mathrm{~h}$, and the $R$. meliloti plates were incubated at $30^{\circ} \mathrm{C}$ with $50 \mu \mathrm{g} / \mathrm{mL}$ chloramphenicol for $15 \mathrm{~h}$. Black bars show the motility for strains expressing bdcA via pMMB206-BdcA and the gray bars indicate the control strains with pMMB206. For each strain, $0.1 \mathrm{mM}$ IPTG was added to induce bdcA expression. ** indicates statistical significant difference as determined by a Student's t-test $(p<$ 0.05). Error bars indicate the standard deviation of two independent cultures. 

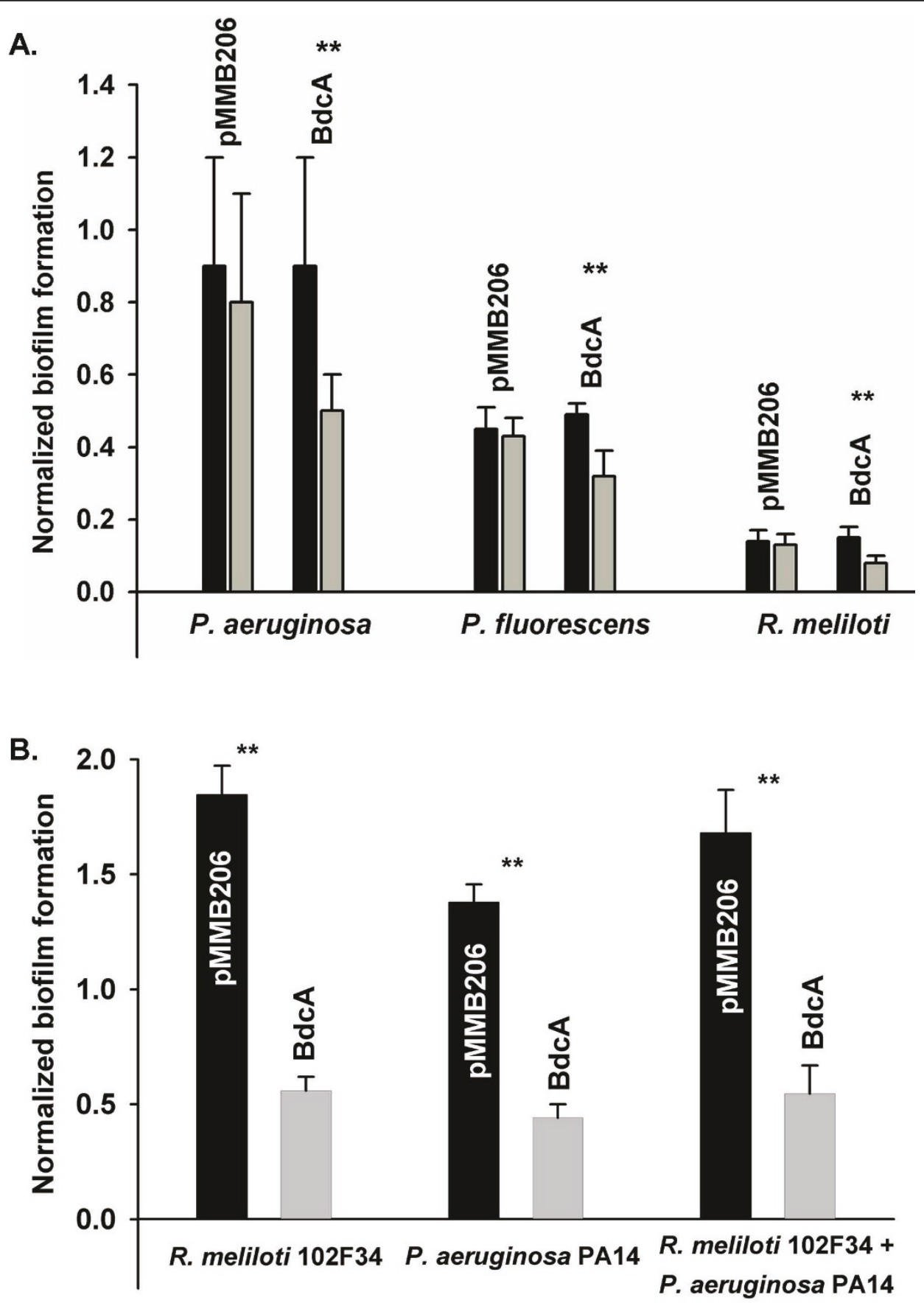

Figure 3 BdcA disperses biofilms in static biofilm tests with 96-well plates. (A) Strains as in the Figure 2 caption. Black bars indicate mature biofilm formation ( $2 \mathrm{~h}$ after IPTG induction for each strain), and the gray bars show biofilm formation after dispersal (19 h after IPTG induction for P. aeruginosa/pMMB206-BdcA and $21.5 \mathrm{~h}$ after IPTG induction for $P$. fluorescens/pMMB206-BdcA and R. meliloti/pMMB206-BdcA). For all three strains, $0.1 \mathrm{mM}$ IPTG was added after $24 \mathrm{~h}$ incubation to induce bdcA expression. The $P$. aeruginosa biofilm was formed at $37^{\circ} \mathrm{C}$ in $L B$ with $250 \mu \mathrm{g} / \mathrm{mL}$ chloramphenicol, the $P$. fluorescens biofilm was formed at $30^{\circ} \mathrm{C} \mathrm{in} \mathrm{LB} \mathrm{with} 250 \mu \mathrm{g} / \mathrm{mL}$ chloramphenicol, and the R. meliloti biofilm was formed at $30^{\circ} \mathrm{C}$ in $\mathrm{LB}$ with $50 \mathrm{\mu g} / \mathrm{mL}$ chloramphenicol. pMMB206 indicates cells with this plasmid, and BdcA indicates cells containing pMMB206-BdcA. (B) For the dual-species biofilms, R. meliloti $\left(30^{\circ} \mathrm{C}\right)$ and $P$. aeruginosa $\left(37^{\circ} \mathrm{C}\right)$ biofilms were formed in $\mathrm{LB}$ for $24 \mathrm{~h}$ then E. coli DH5a/pMMB206-BdcA/pRK2013 was added. The mixed biofilm was developed for $4 \mathrm{~h}$, then IPTG was added for $26 \mathrm{~h}$ to produce BdcA. For the triple species biofilm, the R. meliloti and P. aeruginosa biofilm was formed in $\mathrm{LB}$ for $24 \mathrm{~h}$ at $30^{\circ} \mathrm{C}$, then $E$. coli DH5a/pMMB206-BdcA/ pRK2013 was added. The mixed biofilm was developed for $11 \mathrm{~h}$, then IPTG was added for another $24 \mathrm{~h}$ to produce BdcA. Normalized biofilm is indicated by dividing biofilm formation by cell turbidity. pMMB206 (black bars) indicates cells with this plasmid, and BdcA (gray bars) indicates cells containing pMMB206-BdcA. ** indicates statistical significant difference as determined by a Student's t-test $(p<0.05)$. Error bars indicate the standard deviation of two independent cultures. 
Table 2 Flow cell statistical analysis of biofilm formation via COMSTAT

\begin{tabular}{|c|c|c|c|c|c|c|c|c|}
\hline Time & $\begin{array}{l}\text { Biomass } \\
\left(\mu \mathrm{m}^{3} / \mu \mathrm{m}^{2}\right)\end{array}$ & $\begin{array}{c}\text { Surface coverage } \\
(\%)\end{array}$ & $\begin{array}{l}\text { Average thickness } \\
(\mu \mathrm{m})\end{array}$ & Roughness & $\begin{array}{l}\text { Biomass } \\
\left(\mu \mathrm{m}^{3} / \mu \mathrm{m}^{2}\right)\end{array}$ & $\begin{array}{c}\text { Surface coverage } \\
(\%)\end{array}$ & $\begin{array}{l}\text { Average thickness } \\
(\mu \mathrm{m})\end{array}$ & Roughness \\
\hline & \multicolumn{2}{|c|}{ P. aeruginosa/pMMB206/pP25-gfp } & \multicolumn{6}{|c|}{ P. aeruginosa/pMMB206-BdcA/pP25-gfp } \\
\hline $72 \mathrm{~h}$ & $3 \pm 1$ & $36 \pm 7$ & $6 \pm 3$ & $0.5 \pm 0.3$ & $4 \pm 1$ & $37 \pm 9$ & $8 \pm 3$ & $0.5 \pm 0.2$ \\
\hline $120 \mathrm{~h}$ & $3.1 \pm 0.9$ & $37 \pm 8$ & $7 \pm 3$ & $0.5 \pm 0.2$ & $0.2 \pm 0.1$ & $13 \pm 4$ & $0.5 \pm 0.4$ & $1.6 \pm 0.2$ \\
\hline \multicolumn{3}{|c|}{ R. meliloti /pMMB206/pP25-gfp } & \multicolumn{6}{|c|}{ R. meliloti /pMMB206-BdcA/pP25-gfp } \\
\hline $67 \mathrm{~h}$ & $3 \pm 1$ & $34 \pm 8$ & $6 \pm 2$ & $0.6 \pm 0.3$ & $3 \pm 1$ & $40 \pm 10$ & $6 \pm 2$ & $0.7 \pm 0.2$ \\
\hline $115 \mathrm{~h}$ & $2.8 \pm 0.7$ & $30 \pm 6$ & $6 \pm 2$ & $0.5 \pm 0.1$ & $0.4 \pm 0.3$ & $17 \pm 5$ & $0.9 \pm 0.7$ & $1.3 \pm 0.3$ \\
\hline
\end{tabular}

For $P$. aeruginosa, cultures were grown in LB with $250 \mu \mathrm{g} / \mathrm{mL}$ chloramphenicol and $50 \mu \mathrm{g} / \mathrm{mL}$ carbenicillin for $24 \mathrm{~h}$, then $b d c A$ expression was induced by adding $0.1 \mathrm{mM}$ IPTG. Data were collected at $72 \mathrm{~h}(48 \mathrm{~h}$ after IPTG addition) and $120 \mathrm{~h}(96 \mathrm{~h}$ after IPTG addition). For R. meliloti, cultures were grown in LB with $50 \mu \mathrm{g} / \mathrm{mL}$ chloramphenicol and $50 \mu \mathrm{g} / \mathrm{mL}$ carbenicillin for $24 \mathrm{~h}$, then bdcA expression was induced by adding 0.1 mM IPTG. Data were collected at $67 \mathrm{~h}$ ( $43 \mathrm{~h}$ after IPTG addition) and $115 \mathrm{~h}(91 \mathrm{~h}$ after IPTG addition). Data are the average of two independent cultures for each strain. 
A.

$72 \mathrm{~h}$

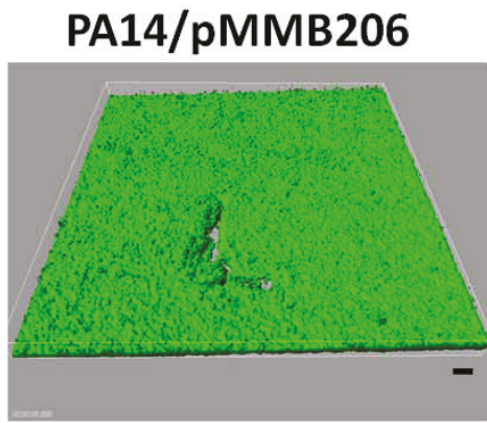

\section{PA14/pMMB206-BdcA}

$120 \mathrm{~h}$
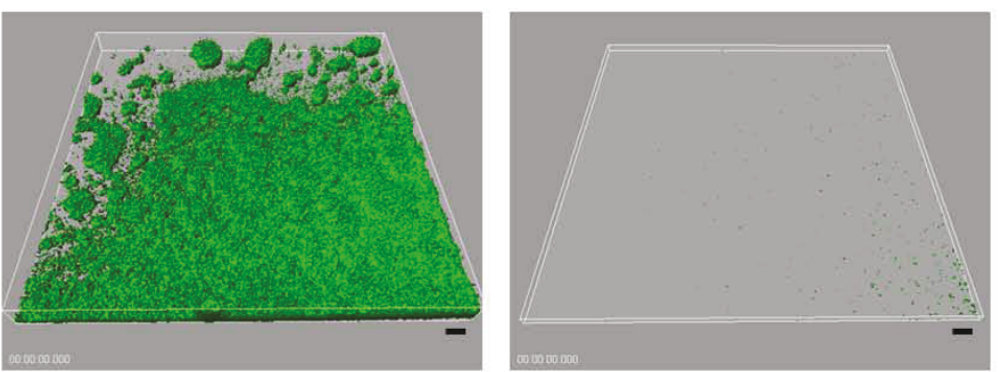

B.

\section{R. meliloti/pMMB206}

R. meliloti/pMMB206-BdcA

$67 \mathrm{~h}$
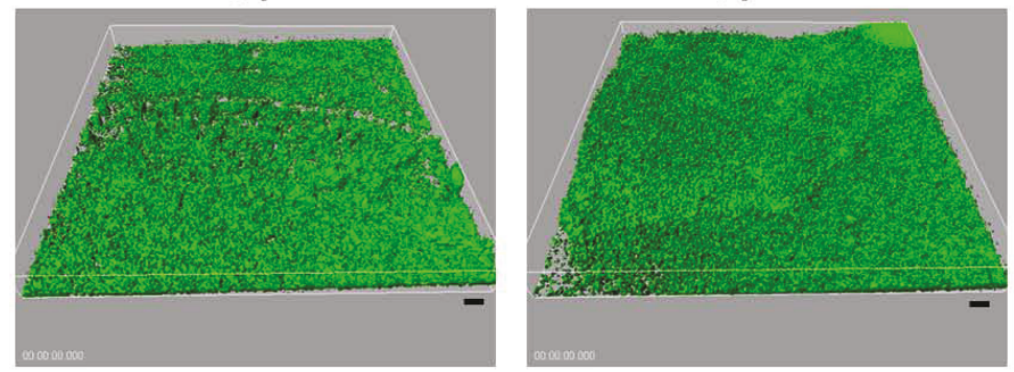

$115 \mathrm{~h}$
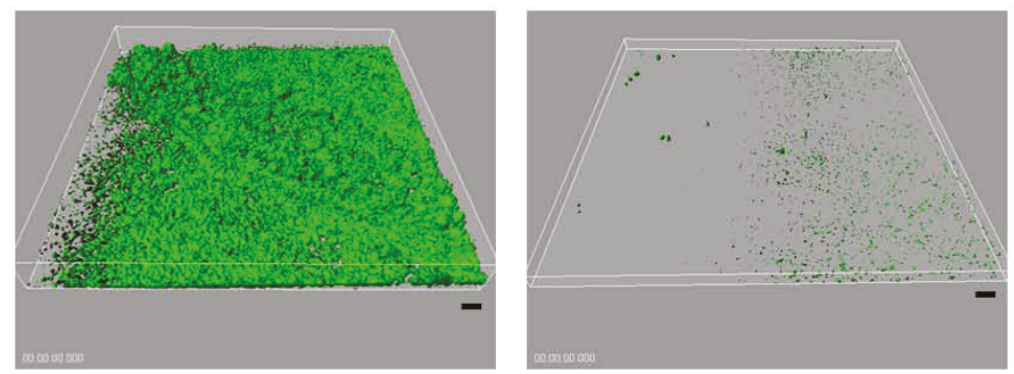

Figure 4 BdcA disperses $P$. aeruginosa and $\boldsymbol{R}$. meliloti biofilms in flow cell experiments. Representative IMARIS images of $P$. aeruginosal pMMB206-BdcA/pP25-gfp and P. aeruginosa/pMMB206/pP25-gfp flow cell biofilm formation after $72 \mathrm{~h}$ and $120 \mathrm{~h}$ of incubation with LB medium at $37^{\circ} \mathrm{C}$ (A). IMARIS images of R. meliloti/pMMB206-BdcA/pP25-gfp and R. meliloti/pMMB206/pP25-gfp flow cell biofilm formation after $67 \mathrm{~h}$ and $115 \mathrm{~h}$ of incubation with LB medium at $30^{\circ} \mathrm{C}$ (B). After forming biofilms in LB for $24 \mathrm{~h}$, IPTG (0.1 mM) was added to induce BdcA production from pMMB206-BdcA. Each strain has pP25-gfp for producing GFP to visualize the biofilms, and carbenicillin $(50 \mu \mathrm{g} / \mathrm{mL})$ was added to retain pP25-gfp. Chloramphenicol $(250 \mu \mathrm{g} / \mathrm{mL}$ for P. aeruginosa and $50 \mu \mathrm{g} / \mathrm{mL}$ for $R$. meliloti) was used to retain the pMMB206-based plasmids. Scale bars represent $10 \mu \mathrm{m}$. 
cultures were used to form biofilms of $R$. meliloti and $P$. aeruginosa. After $24 \mathrm{~h}, \mathrm{BdcA}$ was added to these biofilms by conjugating pMMB206-BdcA from E. coli DH5 $\alpha /$ MMMB206-BdcA/pRK2013; E. coli DH5 $\alpha /$ pMMB206/pRK2013 was used as the negative control which conjugates but does not provide BdcA. Upon producing BdcA for $26 \mathrm{~h}$, total biofilm formation was reduced by $3.3 \pm 0.6$ for $R$. meliloti and $3.1 \pm 0.6$ for $P$. aeruginosa (Figure $3 \mathrm{~B}$ ). For these experiments, the efficiency of transferring pMMB206-BdcA to $R$. meliloti and $P$. aeruginosa was over $76 \%$ and over $80 \%$ respectively, probably due to vast excess of donor $E$. coli cells relative to the recipient cells of the very small biofilm when donor E. coli was added. After conjugation, we checked for the presence of the correct plasmid in recipient cells via PCR for the $b d c A$ gene as well as identified each bacterial species via sequencing for $16 \mathrm{~S}$ rRNA genes to confirm that the selective plating method was accurate. For both tests, all (10) cells from the selective antibiotic plates were found to have the $b d c A$ plasmid (766 bp), and these cells were all determined to be either $P$. aeruginosa or $R$. meliloti, respectively.

In addition, we used the same strategy to treat an existing biofilm formed by both $R$. meliloti and P. aeruginosa and obtained a $3.1 \pm 0.8$-fold biofilm reduction based on BdcA production after conjugation from E. coli strain (Figure 3B). Hence, BdcA was able to disperse a multi-species biofilm that consisted of approximately $40 \% P$. aeruginosa PA14, 23\% $R$. meliloti, and $37 \%$ E. coli (the composition of control biofilm without BdcA was similar at $37 \% P$. aeruginosa PA14, $26 \%$ R. meliloti, and $37 \%$ E. coli). Therefore, BdcA may be introduced into mixed biofilms via conjugation and used to reduce biofilm formation.

\section{Discussion}

Given the near universal nature of c-di-GMP as a biofilm formation and dispersal signal, we investigated whether BdcA from $E$. coli would be effective in removing biofilms from various bacteria. To accomplish this goal, the broad host plasmid pMMB206 was used to express $b d c A$ in different organisms including $P$. aeruginosa, P. fluorescens, and $R$. meliloti. As we had hoped, BdcA production increased swarming and swimming motility and reduced EPS production; these phenotypes indicate a reduced c-diGMP concentration in these strains. The reduced c-diGMP concentrations via BdcA proved extremely effective in dispersing biofilms including that of the opportunistic pathogen $P$. aeruginosa. This is the first report of reducing c-di-GMP via heterologous protein production to cause biofilm dispersal in these three strains. This is an important result in that it is a significant challenge to remove biofilms [30,31] since cells in biofilms are cemented in place by the secreted polymer matrix consisting of polysaccharide, protein, DNA, and lipids [2]; this matrix of the biofilm colony makes most biofilms difficult or impossible to eradicate [4].

BdcA directly reduces bacterial c-di-GMP concentrations [13], and c-di-GMP is a signal that controls physiology of diverse bacteria [32]. In $R$. meliloti, c-di-GMP controls growth, motility, EPS production, and even the interactions between bacteria and host plants [33]. In $P$. aeruginosa, c-di-GMP controls various cell activities including biofilm formation, EPS production, and aggregation [22]. Hence, BdcA may control biofilm dispersal in as many organisms as c-di-GMP functions as a second messenger. In addition, $b d c A$ shows high sequence conservation with other species (including Pseudomonas and Rhizobium) and is well conserved in many bacteria [13]. Hence, BdcA may be used for dispersal in many strains. As a preliminary proof of this principle, our results demonstrate the feasibility of introducing BdcA into existing non-E. coli biofilms (formed by $P$. aeruginos $a$ and R. meliloti individually, as well as by mixed biofilms of these two bacteria) via conjugation of a broad-host-range plasmid) to reduce total biofilm formation. Therefore, in this study, we successfully disperse biofilms of disparate strains simply by producing BdcA. Hence, through this genetic approach, a single protein may be used to remove biofilms rather than by using traditional chemical or physical means.

\section{List of abbreviations}

c-di-GMP: cyclic diguanylate; IPTG: isopropyl- $\beta$-D-thiogalactopyranoside; LB: Luria-Bertani; GFP: green fluorescent protein.

\section{Acknowledgements}

This work was supported by the National Institutes of Health (R01 GM089999). T.W. is the T. Michael O'Connor Endowed Professor at Texas A \& M University.

\section{Authors' contributions}

TKW and QM designed the study and wrote the paper. QM and GZ performed the experiments and analyzed the results.

\section{Competing interests}

The authors declare that they have no competing interests.

Received: 23 June 2011 Accepted: 26 October 2011

Published: 26 October 2011

\section{References}

1. Heilmann C, Götz F: Cell-cell communication and biofilm formation in Gram-positive bacteria. In Bacterial Signaling. Edited by: Krämer R, Jung K. Weinheim: Wiley-Blackwell; 2010:

2. Flemming HC, Wingender J: The biofilm matrix. Nat Rev Microbiol 2010, 8:623-633.

3. Walker JT, Bradshaw DJ, Bennett AM, Fulford MR, Martin MV, Marsh PD: Microbial biofilm formation and contamination of dental-unit water systems in general dental practice. Appl Environ Microbiol 2000, 66:3363-3367.

4. Kaplan JB: Biofilm dispersal: mechanisms, clinical implications, and potential therapeutic uses. J Dent Res 2010, 89:205-218.

5. Sauer K, Richkard AH, Davies DG: Biofilms and biocomplexity. Microb 2007, 2:347-353. 
6. Characklis WG, Nevimons MJ, Picologlou BF: Influence of fouling biofilms on heat transfer. Heat Transfer Eng 1981, 3:23-27.

7. Schwermer CU, Lavik G, Abed RM, Dunsmore B, Ferdelman TG, Stoodley P, Gieseke A, de Beer D: Impact of nitrate on the structure and function of bacterial biofilm communities in pipelines used for injection of seawater into oil fields. Appl Environ Microbiol 2008, 74:2841-2851.

8. Rosche B, Li XZ, Hauer B, Schmid A, Buehler K: Microbial biofilms: a concept for industrial catalysis? Trends Biotechnol 2009, 27:636-643.

9. Kiely PD, Call DF, Yates MD, Regan JM, Logan BE: Anodic biofilms in microbial fuel cells harbor low numbers of higher-power-producing bacteria than abundant genera. Appl Microbiol Biotechnol 2010, 88:371-380.

10. Wood TK, Hong SH, Ma Q: Engineering biofilm formation and dispersal. Trends Biotechnol 2011, 29:87-94.

11. Wood TK, González Barrios AF, Herzberg M, Lee J: Motility influences biofilm architecture in Escherichia coli. Appl Microbiol Biotechnol 2006, 72:361-367.

12. Van Houdt R, Michiels CW: Role of bacterial cell surface structures in Escherichia coli biofilm formation. Res Microbiol 2005, 156:626-633.

13. Ma Q, Yang Z, Pu M, Peti W, Wood TK: Engineering a novel c-di-GMPbinding protein for biofilm dispersal. Environ Microbiol 2011, 13:631-642.

14. Karatan E, Watnick P: Signals, regulatory networks, and materials that build and break bacterial biofilms. Microbiol Mol Biol Rev 2009, 73:310-347.

15. Saiman L, Siegel J: Infection control in cystic fibrosis. Clin Microbiol Rev 2004, 17:57-71

16. Lyczak JB, Cannon CL, Pier GB: Lung infections associated with cystic fibrosis. Clin Microbiol Rev 2002, 15:194-222.

17. Haas $D$, Keel $C$ : Regulation of antibiotic production in root-colonizing Pseudomonas spp. and relevance for biological control of plant disease. Annu Rev Phytopathol 2003, 41:117-153.

18. Girlanda M, Perotto S, Moenne-Loccoz Y, Bergero R, Lazzari A, Defago G Bonfante P, Luppi AM: Impact of biocontrol Pseudomonas fluorescens $\mathrm{CHAO}$ and a genetically modified derivative on the diversity of culturable fungi in the cucumber rhizosphere. Appl Environ Microbiol 2001, 67:1851-1864.

19. Szeto WW, Nixon BT, Ronson CW, Ausubel FM: Identification and characterization of the Rhizobium meliloti ntrC gene: $R$. meliloti has separate regulatory pathways for activation of nitrogen fixation genes in free-living and symbiotic cells. J Bacteriol 1987, 169:1423-1432.

20. Eardly BD, Materon LA, Smith NH, Johnson DA, Rumbaugh MD, Selander RK: Genetic structure of natural populations of the nitrogenfixing bacterium Rhizobium meliloti. Appl Environ Microbiol 1990, 56:187-194.

21. Sambrook J, Fritsch EF, Maniatis T: Molecular Cloning, A Laboratory Manual. Cold Spring Harbor, NY: Cold Spring Harbor Laboratory Press; 1989

22. Ueda A, Wood TK: Connecting quorum sensing, c-di-GMP, pel polysaccharide, and biofilm formation in Pseudomonas aeruginosa through tyrosine phosphatase TpbA (PA3885). PLoS Pathog 2009, 5 : e1000483.

23. Morales VM, Backman A, Bagdasarian M: A series of wide-host-range lowcopy-number vectors that allow direct screening for recombinants. Gene 1991, 97:39-47.

24. Fletcher $\mathrm{M}$ : The effects of culture concentration and age, time, and temperature on bacterial attachment to polystyrene. Can J Microbiol 1977, 23:1-6.

25. Kellogg CA, Galkiewicz JP: Cross-kingdom amplification using bacteriaspecific primers: complications for studies of coral microbial ecology. Appl Environ Microbiol 2008, 74:7828-7831.

26. Yang $\mathrm{X}, \mathrm{Ma} \mathrm{Q}$, Wood TK: The R1 conjugative plasmid increases Escherichia coli biofilm formation through an envelope stress response. Appl Environ Microbiol 2008, 74:2690-2699.

27. Goodman AL, Kulasekara B, Rietsch A, Boyd D, Smith RS, Lory S: A signaling network reciprocally regulates genes associated with acute infection and chronic persistence in Pseudomonas aeruginosa. Dev Cell 2004, 7:745-754

28. Sperandio V, Torres AG, Kaper JB: Quorum sensing Escherichia coli regulators $B$ and $C$ ( $Q$ seBC): a novel two-component regulatory system involved in the regulation of flagella and motility by quorum sensing in E. coli. Mol Microbiol 2002, 43:809-821.

29. Zhang XS, García-Contreras R, Wood TK: Escherichia coli transcription factor YncC (McbR) regulates colanic acid and biofilm formation by repressing expression of periplasmic protein YbiM (McbA). ISME J 2008, 2:615-631.

30. del Pozo JL, Patel R: The challenge of treating biofilm-associated bacterial infections. Clin Pharmacol Ther 2007, 82:204-209.

31. Bardouniotis E, Huddleston W, Ceri H, Olson ME: Characterization of biofilm growth and biocide susceptibility testing of Mycobacterium phlei using the $\mathrm{MBEC}^{\mathrm{TM}}$ assay system. FEMS Microbiol Lett 2001, 203:263-267.

32. D'Argenio DA, Miller Sl: Cyclic di-GMP as a bacterial second messenger. Microbiology 2004, 150:2497-2502

33. Wang $Y, X u$ J, Chen A, Zhu J, Yu G, Xu L, Luo L: GGDEF and EAL proteins play different roles in the control of Sinorhizobium meliloti growth, motility, exopolysaccharide production, and competitive nodulation on host alfalfa. Acta Biochim Biophys Sin 2010, 42:410-417.

34. Baba T, Ara T, Hasegawa M, Takai Y, Okumura Y, Baba M, Datsenko KA, Tomita M, Wanner BL, Mori H: Construction of Escherichia coli K-12 inframe, single-gene knockout mutants: the Keio collection. Mol Syst Biol 2006, 2:2006 0008 .

35. Surette MG, Miller MB, Bassler BL: Quorum sensing in Escherichia coli, Salmonella typhimurium, and Vibrio harveyi: a new family of genes responsible for autoinducer production. Proc Natl Acad Sci USA 1999, 96:1639-1644.

36. Liberati NT, Urbach JM, Miyata S, Lee DG, Drenkard E, Wu G, Villanueva J, Wei T, Ausubel FM: An ordered, nonredundant library of Pseudomonas aeruginosa strain PA14 transposon insertion mutants. Proc Natl Acad SCi USA 2006, 103:2833-2838.

37. Figurski DH, Helinski DR: Replication of an origin-containing derivative of plasmid RK2 dependent on a plasmid function provided in trans. Proc Natl Acad Sci USA 1979, 76:1648-1652.

doi:10.1186/1756-0500-4-447

Cite this article as: Ma et al:: Escherichia coli BdcA controls biofilm dispersal in Pseudomonas aeruginosa and Rhizobium meliloti. BMC Research Notes 2011 4:447.

\section{Submit your next manuscript to BioMed Central and take full advantage of:}

- Convenient online submission

- Thorough peer review

- No space constraints or color figure charges

- Immediate publication on acceptance

- Inclusion in PubMed, CAS, Scopus and Google Scholar

- Research which is freely available for redistribution

Submit your manuscript at www.biomedcentral.com/submit
Ciomed Central 